\title{
Schooling Vs Home Education: Implications in Measuring Success in Home Education in the United Kingdom
}

\author{
Fadoua Govaerts \\ University of Bath
}

\begin{abstract}
.
This paper aims to address the current limitations of measuring success in Home Education. Educational achievements in schools are measured through standard knowledge based assessments which take place during various stages in a child's formal education, based on the National Curriculum. However, due to the unique purpose, aims and methods used by Home Educators, current measurements and standards are incompatible with achievements identified by Home Educating families.

The established traditional concepts of educational success are the framework of current measurement of educational achievements, which may be contrary to the concepts of families who follow different philosophical understandings of education. The reality of each family having their individual aims and purpose of Home Education has resulted in their achievements to be immeasurable by the traditional standards as used in schools.

This paper aims to argue that it is necessary to review current philosophical and theoretical concepts in education, apart from knowledge-based education as set out by the state in the National Curriculum. This will allow us to develop new common grounds in measurement of educational success inclusive of individual achievements set out by Home Educators.
\end{abstract}

Keywords: Home Education; Alternative Education; Educational Achievement; Autonomous Learning 